\title{
Prophylactic indomethacin: systematic review and meta-analysis
}

\author{
Peter W Fowlie
}

\begin{abstract}
Aims-To examine the effectiveness of prophylactic intravenous indomethacin in reducing the mortality and morbidity associated with patent ductus arteriosus and intraventricular haemorrhage in infants weighing less than $1750 \mathrm{~g}$ at birth. Method-A literature search from 1980 onwards was made of three databases: Medline; Embase; and the Oxford Database of Perinatal Trials. Using strict criteria applied to randomised controlled trials only, two observers independently selected 14 studies for inclusion in the review. The methodological quality of each study was assessed independently by two observers using explicit criteria. Data on relevant outcome measures were extracted on two separate occasions. Where appropriate, the results of individual trials were combined using metaanalysis techniques to provide a pooled estimate of effect.
\end{abstract}

Results-There is a trend towards reduced neonatal mortality in infants receiving prophylactic indomethacin, pooled estimate of risk difference $-0.025(95 \%$ confidence interval (CI) $-0.061,0.010)$. The incidence of symptomatic patent ductus arteriosus is significantly reduced in treated infants, pooled estimate of risk difference -0.217 $(95 \%$ CI $-0.275,-0 \cdot 160)$, but there is no evidence that treatment affects respiratory outcomes. Prophylactic indomethacin significantly reduces the incidence of grades 3 and 4 intraventricular haemorrhage in treated infants, pooled estimate of risk difference $-0.039(95 \%$ CI -0.066 , $-0.011)$. However, there is no sound evidence assessing the long term effect of prophylaxis on neurodevelopmental outcome. Although there is a trend in treated infants towards an increased incidence of necrotising enterocolitis, pooled estimate of risk difference $0.015(95 \%$ CI -0.002 , $0 \cdot 033)$, and some evidence that treatment may transiently impair renal function, there is no evidence that haemostasis is disturbed.

Conclusion-Prophylactic treatment with indomethacin has several immediate benefits. However, more data are needed on the incidence of possible adverse effects and neurodevelopmental outcomes before routine use of this therapy can be recommended.

(Arch Dis Child 1996; 74: F81-F87)

Keywords: overview, pooled estimate, very low birthweight, intraventricular haemorrhage, patent ductus arteriosus.

Premature infants with a patent ductus arteriosus (PDA) are at increased risk of more prolonged and more severe respiratory distress syndrome, bronchopulmonary dysplasia, and death compared with similar infants whose ductuses have closed. ${ }^{1}$ This prompted surgical intervention ${ }^{2}$ and, later, pharmacological treatment using indomethacin ${ }^{3}$ in an attempt to improve the outcome in these infants. Because treatments that closed the patent ductus potentially influence the pulmonary circulation, the early outcomes examined included measures of ventilatory support, pneumothorax, chronic lung disease and mortality. It was subsequently suggested that medical treatment, comprising a variety of mechanisms, ${ }^{4-6}$ might prevent intraventricular haemorrhage (IVH).

Treatment with prophylactic indomethacin may, however, be associated with serious adverse effects. By reducing cerebral blood flow, indomethacin may increase the risk of cerebral hypoxia. ${ }^{7}$ It remains essential, therefore, to consider long term neurodevelopmental outcomes, as this potential adverse effect may outweigh any benefit from a possible reduction in the incidence of intraventricular haemorrhage. Similarly, although closure of the patent ductus may be expected to reduce the incidence of necrotising enterocolitis, this needs to be balanced against any effect indomethacin might have directly on gut blood flow. ${ }^{8}$ Indomethacin may also reduce renal blood flow, thus impairing renal function. ${ }^{9}$ It may interfere with platelet aggregation, thus impairing haemostasis. ${ }^{10}$ If there is a potential effect on the microvasculature and cerebral blood flow the incidence of retinopathy of prematurity may be affected by treatment. Finally, there has been at least one report of indomethacin being associated with an increased risk of sepsis. ${ }^{11}$

Potential adverse effects must be considered, particularly when assessing the overall effect of prophylaxis. Only some infants will
DD1 9SY.

Accepted 16 November 1995 
ever actually experience a patent ductus arteriosus and/or intraventricular haemorrhage, and it is only this proportion of the infant population that could benefit from prophylaxis. However, as all infants would be exposed to the treatment through prophylaxis, all of them would be exposed to possible harm. Using the evidence of individual trials to date, neonatologists are uncertain about the benefit(s) of prophylaxis, if any, and remain concerned in case this intervention might, in fact, do more harm than good.

One method of summarising evidence that can provide a more accurate and precise estimate of treatment effect, by minimising the bias and random error which can influence the results of individual trials, is the systematic review of all known trials. ${ }^{12} \mathrm{~A}$ systematic search for reviews of prophylaxis in very low birthweight infants failed to identify any that provided explicit details of how the review was conducted. This study, therefore, presents the methods and results of a systematic review and, where appropriate, meta-analyses of the evidence examining the effectiveness of prophylactic indomethacin in reducing mortality and morbidity in infants weighing less than $1750 \mathrm{~g}$ at birth.

\section{Methods}

A literature search (English only) was undertaken in three databases: Medline (at the National Library of Medicine, Bethesda, USA) (1980 to September 1994); Embase (1974-94) in DIALOG; and the Oxford Database of Perinatal Trials (ODPT) (Version 1.3, Disk issue 7, Spring 1992). This strategy identified 86 articles and abstracts. One further abstract was identified from the author's personal files. A search by first author of any abstracts was done in the Science Citation Index to try and identify any corresponding full manuscripts published. None was identified. The following types of articles were excluded: letters; editorials/commentaries; reviews; lectures; unpublished studies; and studies in progress. This left 70 articles and abstracts to be assessed for possible inclusion in the review, of which two could not be obtained for assessment.

To be included in the review, trials had to meet each of four criteria

- the study infants had to be newborn with a maximum birthweight of $1750 \mathrm{~g}$ (studies

Table 1 Outcomes on which data are presented

Outcome

Neonatal mortality

Symptomatic patent ductus arteriosus

All patent ductus arteriosus

Pneumothorax

Duration of assisted ventilation

Chronic lung disease

Duration of oxygen dependence

Intraventricular haemorrhage

Intraventricular haemorrhage (grades 3 or 4 )

Intraventricular haemorrhage that progresses

Neurodevelopmental outcome

Necrotising enterocolitis

Renal function

Haemostasis

Retinopathy of prematurity

Septic episodes with a lower weight limit were also included)

- the intervention had to be prophylactic treatment with intravenous indomethacin given within 24 hours of birth

- the study had to be a randomised controlled trial

- the study had to include some measure of at least one of the outcomes listed in table 1

Each of the 68 available articles identified by the literature search was assessed independently, using the inclusion criteria, by the author and a colleague training in research methodology. Agreement beyond chance on which articles to include or exclude was measured using Cohen's kappa (0.93) statistic and any disagreement was resolved by discussion. In this way 19 articles/abstracts were initially selected for inclusion in the review.

As yet, there is no universally accepted way to assess the methodological quality (validity) of clinical trials. ${ }^{13}$ For this study, having preselected only randomised controlled trials, the author chose to base validity assessment on four methodological criteria that can be associated with significant bias in trials assessing treatment effect. ${ }^{14}$

(1) Was there adequate concealment of randomisation? (Inadequate concealment leads to an overestimate of treatment effect.)

(2) Were those caring for the study subjects blind to treatment group allocation? (Unblinding leads to exaggerated treatment effects being seen.)

(3) Were $>90 \%$ of those initially randomised included in the final outcome analysis reported? (If, for whatever reason, a significant proportion of those randomised are not included, results may be biased in either direction.)

(4) Were those assessing the outcome blinded to treatment allocation? (Unblinding again causes an overestimate of treatment effect.)

No scoring system is incorporated in this particular method of quality assessment. The final interpretation of the validity of the studies included in the review is, therefore, left to the individual reader.

On the basis of the four criteria described above, the same two investigators that selected the articles for inclusion independently assessed the methodology reported in each article/abstract. For each of the four criteria, agreement beyond chance, measured by Cohen's kappa, was as follows: method of treatment allocation, 0.73 ; blinding of care giver, $0.90 ;>90 \%$ follow up, 0.51 ; and blinding of person assessing outcome, 0.64. Disagreement was settled by discussion. Sixty six per cent of disagreement was found to be due to simple misreading.

Each article was reviewed by the author and the outcomes measured were recorded, initially without specific data. On two separate occasions the data were then extracted from the articles/abstracts and checked for consistency. Any discrepancies were resolved by a third data extraction. The data taken from abstracts were compared with data taken from full manuscripts by the same author(s) to try 
Table 2 Characteristics of trials included in the review

\begin{tabular}{|c|c|c|c|c|c|c|c|c|c|}
\hline Author & Year & Reference & $\begin{array}{l}\text { Infants' weight } \\
(\mathrm{g})\end{array}$ & $\begin{array}{l}\text { Indomethacin } \\
\text { dose }(\mathrm{mg} / \mathrm{kg})\end{array}$ & Route & $\begin{array}{l}\text { Time of } \\
\text { first dose }\end{array}$ & Frequency & Control & $\begin{array}{l}\text { Study size } \\
\text { (treatment + control) }\end{array}$ \\
\hline $\begin{array}{l}\text { Setzer } \\
\text { Mahoney } \\
\text { Ment } \\
\text { Puckett } \\
\text { Vincer } \\
\text { Rennie } \\
\text { Bandstra† } \\
\text { Krueger } \\
\text { Hanigan }\end{array}$ & $\begin{array}{l}1984 \\
1985 \\
1985 \\
1985 \\
1985 \\
1986 \\
1987 \\
1987 \\
1988\end{array}$ & $\begin{array}{l}22 \\
23 \\
24 \\
25 \\
26 \\
27 \\
28 \\
29 \\
30\end{array}$ & $\begin{aligned} &< 1300 \\
& 700-1300 \\
& 600-1250 \\
&< 1400 \\
&<1500 \\
&<1750 \\
&<1300 \\
& 750-1500 \\
&< 1500\end{aligned}$ & $\begin{array}{l}0 \cdot 2 ; 0 \cdot 1 ; 0 \cdot 1 \\
0 \cdot 2 ; 0 \cdot 1 ; 0 \cdot 1 \\
0 \cdot 2 ; 0 \cdot 1 \times 4^{\star} \\
0 \cdot 2 \times 3 \\
0 \cdot 2 \times 3 \\
0 \cdot 2 \times 3 \\
0 \cdot 2 ; 0 \cdot 1 ; 0 \cdot 1 \\
0 \cdot 2 \\
0 \cdot 1 \times 4\end{array}$ & $\begin{array}{l}\text { IV } \\
\text { IV } \\
\text { IV } \\
\text { IV } \\
\text { IV } \\
\text { IV } \\
\text { IV } \\
\text { IV } \\
\text { IV }\end{array}$ & $\begin{array}{l}<12 \text { hours } \\
12-18 \text { hours } \\
6 \text { hours } \\
<24 \text { hours } \\
12 \text { hours } \\
<24 \text { hours } \\
<12 \text { hours } \\
24 \text { hours } \\
<12 \text { hours }\end{array}$ & $\begin{array}{l}12 \text { hourly } \\
12 \text { hourly } \\
12 \text { hourly } \\
12 \text { hourly } \\
24 \text { hourly } \\
12 \text { hourly } \\
12 \text { hourly } \\
\text { Stat. } \\
12 \text { hours between dose } \\
1 \text { and } 2 \text { then } 24 \text { hourly }\end{array}$ & $\begin{array}{l}\text { Placebo } \\
\text { Placebo } \\
\text { Placebo } \\
\text { Placebo } \\
\text { Placebo } \\
\text { Placebo } \\
\text { Placebo } \\
\text { Placebo }\end{array}$ & $\begin{array}{r}59(29+30) \\
104(51+53) \\
48(24+24) \\
32(16+16) \\
30(15+15) \\
50(24+26) \\
123(64+59) \\
32(15+17) \\
111(55+56)\end{array}$ \\
\hline $\begin{array}{l}\text { Ment } \\
\text { Bandstra } \\
\text { Bada } \\
\text { Ment } \\
\text { Ment }\end{array}$ & $\begin{array}{l}1988 \\
1988 \\
1989 \\
1994 \\
1994\end{array}$ & $\begin{array}{l}31 \\
32 \\
33 \\
34 \\
35\end{array}$ & $\begin{array}{l}600-1250 \\
<1300 \\
<1500 \\
600-1250 \\
600-1250\end{array}$ & $\begin{array}{l}0 \cdot 1 \times 3 \\
0 \cdot 2 ; 0 \cdot 1 ; 0 \cdot 1 \\
0 \cdot 2 ; 0 \cdot 1 ; 0 \cdot 1 \\
0 \cdot 1 \times 3 \\
0 \cdot 1 \times 3\end{array}$ & $\begin{array}{l}\text { IV } \\
\text { IV } \\
\text { IV } \\
\text { IV } \\
\text { IV }\end{array}$ & $\begin{array}{l}6-10 \text { hours } \\
<12 \text { hours } \\
6 \text { hours } \\
6-12 \text { hours } \\
6-12 \text { hours }\end{array}$ & $\begin{array}{l}12 \text { hourly } \\
12 \text { hourly } \\
12 \text { hourly } \\
24 \text { hourly } \\
24 \text { hourly }\end{array}$ & $\begin{array}{l}\text { Placebo } \\
\text { Placebo } \\
\text { Placebo } \\
\text { Placebo } \\
\text { Placebo }\end{array}$ & $\begin{array}{c}36(19+17) \\
199(99+100) \\
141(71+70) \\
61(27+34) \\
431(209+222)\end{array}$ \\
\hline
\end{tabular}

^Dosage schedule changed to $0 \cdot 1 \mathrm{mg} / \mathrm{kg} /$ dose $\times 5$ early in trial after concern about diminished urine output in treated infants.

tThis abstract reports neurodevelopmental follow up on 123 of the 199 infants enrolled in the trial more fully reported by Bandstra in 1988.

and avoid duplicating data. On the basis of the date of the study, the size of the treatment and control groups, and the raw data available, five abstracts $^{15-19}$ were thought to provide data subsequently published in a full manuscript. All five abstracts, none of which contributed any unique data, were therefore dropped from the review.

Dichotomous outcomes are expressed in three ways. The event rate ratio (ERR) is the event rate in the treatment group as a proportion of the event rate in the control group. The event rate difference (ERD) is the difference in event rate between the treatment group and the control group. The number needed to treat (NNT) is the inverse of the event rate difference, and is the number of subjects that one expects will need to be treated to prevent one subject having the adverse outcome. A fixed effect model is used to calculate the pooled event rate ratio and the pooled event rate difference. ${ }^{20}$ Continuous data are expressed as a mean difference and weighted mean difference in the meta-analyses. ${ }^{21}$ Ninety five per cent confidence intervals (CI) are provided throughout.

\section{Results}

Fourteen reports were finally selected for inclusion in the review. ${ }^{22-35}$ The characteristics of the trials, as reported, are summarised in table 2 .

The important methodologies used in each trial are summarised in table 3 . From the published reports, four of the 14 trials met all four

Table 3 Methodological quality (validity) of trials included in the review

\begin{tabular}{lllllll}
\hline Author & Year & Reference & $\begin{array}{l}\text { Method of } \\
\text { randomisation }\end{array}$ & $\begin{array}{l}\text { Blinding } \\
\text { of carer }\end{array}$ & $\begin{array}{l}>90 \% \\
\text { follow up }\end{array}$ & $\begin{array}{l}\text { Blinding of } \\
\text { outcome assessor }\end{array}$ \\
\hline Setzer & 1984 & 22 & Not described & Yes & Yes & Yes \\
Mahoney & 1985 & 23 & Phone/coded drugs & Yes & Yes & Yes \\
Ment & 1985 & 24 & Not described & Yes & Yes & Yes \\
Puckett & 1985 & 25 & Not described & $?$ & No & Yes \\
Vincer & 1985 & 26 & Not described & Yes & Yes & Yes \\
Rennie & 1986 & 27 & Not described & $?$ & Yes & $?$ \\
Bandstra & 1987 & 28 & Not described & $?$ & No & $?$ \\
Krueger & 1987 & 29 & Not described & No & Yes & Yes \\
Hanigan & 1988 & 30 & Envelopes & Yes & Yes & Yes \\
Ment & 1988 & 31 & Not described & Yes & Yes & Yes \\
Bandstra & 1988 & 32 & Envelopes & Yes & Yes & Yes \\
Bada & 1989 & 33 & Not described & $?$ & Yes & Yes \\
Ment & 1994 & 34 & Not described & $?$ & Yes & Yes \\
Ment & 1994 & 35 & Phone/coded drugs & $?$ & Yes &
\end{tabular}

«This abstract reports unique data from a subset of the infants enrolled in the same trial described more fully by Bandstra in 1988 . methodological criteria; four met three of the criteria; three met two; and one trial met only one of the criteria. Two trials (both reported in abstract only) did not meet any of the criteria.

Where appropriate, individual trial results are presented in table form along with a pooled estimate of the treatment effect derived from a meta-analysis. For outcomes where meta-analysis was not possible, an overview of the available data is given. The number of trials, along with the total number of infants providing data towards any of the analyses, are found either in the tables or separately in the text.

\section{NEONATAL MORTALITY}

The results shown in table 4 show there is no significant difference in neonatal mortality between the treatment and placebo groups. However, the confidence intervals around the pooled estimates suggest a trend toward a reduction in mortality in those infants treated with prophylactic indomethacin.

PATENT DUCTUS ARTERIOSUS

Prophylactic indomethacin reduces the incidence of 'symptomatic' PDA (PDA associated with signs/symptoms of congestive heart failure) (table 5). The incidence of echo-diagnosed PDA - that is, the sum of all patent ductuses whether symptomatic or not, is reduced even further by prophylactic indomethacin (five trials, ${ }^{24} 31323435623$ infants); pooled $\mathrm{ERR}=0.304(95 \%$ CI $0.220,0.417)$, pooled $\mathrm{ERD}=-0.289(95 \%$ CI $-0.353,-0.225)$, $\mathrm{NNT}=4$.

\section{PULMONARY OUTCOMES}

The pooled results of three trials, ${ }^{27} 3032$ (360 infants) reporting the incidence of pneumothorax show no significant difference between the treatment and placebo groups; pooled $E R R=0.790(95 \%$ CI $0.490,1.271)$; pooled $\mathrm{ERD}=-0.022(95 \% \mathrm{CI}-0.093,0.048)$. The pooled mean difference, $-3.179(95 \% \mathrm{CI}$ $-7 \cdot 170,0.811)$, in the duration of ventilation (days) required between the treatment and placebo groups is not significant (three trials, ${ }^{23} 3033356$ infants). Only one trial, by 
Table 4 Results and meta-analysis of trials providing outcome data on neonatal mortality

\begin{tabular}{|c|c|c|c|c|c|c|c|}
\hline \multirow[b]{2}{*}{ Author } & \multirow[b]{2}{*}{ Year } & \multirow[b]{2}{*}{ Reference } & \multicolumn{2}{|l|}{ Outcome } & \multirow[b]{2}{*}{$E R R(95 \% C I)$} & \multirow[b]{2}{*}{$E R D(95 \% C I)$} & \multirow[b]{2}{*}{$N N T$} \\
\hline & & & Treated & Control & & & \\
\hline $\begin{array}{l}\text { Puckett } \\
\text { Ment } \\
\text { Mahoney } \\
\text { Vincer } \\
\text { Rennie } \\
\text { Krueger } \\
\text { Hanigan } \\
\text { Bandstra } \\
\text { Ment } \\
\text { Bada } \\
\text { Ment } \\
\text { Ment }\end{array}$ & $\begin{array}{l}85 \\
85 \\
85 \\
85 \\
86 \\
87 \\
88 \\
88 \\
88 \\
89 \\
94 \\
94\end{array}$ & $\begin{array}{l}25 \\
24 \\
23 \\
26 \\
27 \\
29 \\
30 \\
32 \\
31 \\
33 \\
34 \\
35\end{array}$ & $\begin{array}{c}3 / 16 \\
1 / 24 \\
10 / 51 \\
3 / 15 \\
2 / 14 \\
2 / 15 \\
13 / 56 \\
10 / 99 \\
0 / 19 \\
9 / 71 \\
7 / 27 \\
16 / 209\end{array}$ & $\begin{array}{c}3 / 16 \\
4 / 24 \\
10 / 53 \\
2 / 15 \\
8 / 26 \\
4 / 17 \\
8 / 56 \\
9 / 100 \\
1 / 17 \\
12 / 70 \\
5 / 34 \\
29 / 222\end{array}$ & $\begin{array}{l}1.000(0.236,4.232) \\
0.250(0.030,2.076) \\
1.039(0.473,2.85) \\
1.500(0.291,7.737) \\
0.677(0.257,1.786) \\
0.567(0.121,2.667) \\
1.625(0.730,3.615) \\
1.122(0.476,2.642) \\
0.299(0.013,6.867) \\
0.739(0.332,1.644) \\
1.763(0.629,4.943) \\
0.586(0.328,1.047)\end{array}$ & $\begin{array}{r}0.000(-0.270,0.270) \\
-0.125(-0.294,0.044) \\
0.007(-0.144,0.158) \\
0.067(-0.200,0.334) \\
-0.099(-0.340,0.142) \\
-0.102(-0.367,0.163) \\
0.089(-0.054,0.232) \\
0.011(-0.071,0.093) \\
-0.060(-0.209,0.089) \\
-0.045(-0.163,0.073) \\
0.112(-0.092,0.316) \\
-0.054(-0.111,0.003)\end{array}$ & \\
\hline \multicolumn{5}{|c|}{ Pooled estimate } & $0.870(0.660,1.145)$ & $-0.025(-0.061,0.010)$ & 40 \\
\hline
\end{tabular}

Mahoney, 23 looked at the duration of oxygen dependence (days): the difference between the two groups, $-3.0(95 \% \mathrm{CI}-18 \cdot 13,12 \cdot 13)$, is not significant. The incidence of chronic lung disease seen in trials reporting this outcome (however defined)does not differ among the

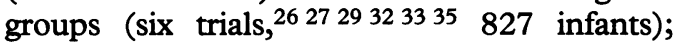
pooled $\mathrm{ERR}=1.056(95 \%$ CI $0.882,1.262)$; pooled $\mathrm{ERD}=0.007(95 \% \mathrm{CI}-0.049,0.063)$.

INTRAVENTRICULAR HAEMORRHAGE

The incidence of IVH of all grades is significantly reduced in infants who receive prophylactic indomethacin (table 6). An analysis of the trials providing data on grades 3 and 4 haemorrhage shows this effect is still present and the incidence of severe IVH is reduced in the treatment group by about $40 \%$ (table 7 ). There is no evidence, however, that prophylactic indomethacin reduces the incidence of intraventricular haemorrhage (grade 1) that progresses (two trials, ${ }^{33} 3483$ infants); pooled $\mathrm{ERR}=0.805(95 \%$ CI 0.441, 1.467); pooled $\mathrm{ERD}=-0.081(95 \% \mathrm{CI}-0.292,0 \cdot 130)$.

\section{NEURODEVELOPMENTAL OUTCOME}

The effect of prophylactic indomethacin on long term neurodevelopmental outcome has been described only by Bandstra (abstract). ${ }^{32}$ There is no evidence of a significant difference between the treatment and placebo groups when assessed using the Bayley Mental and Physical Developmental Index at between 12 and 24 months, although Bandstra reported a trend toward a lower incidence of abnormal physical scores in the indomethacin group.

\section{NECROTISING ENTEROCOLITIS}

The pooled estimates of the effect on the incidence of necrotising enterocolitis do not quite reach significance (eight trials, ${ }^{23} 24262931-3335$ 1047 infants); pooled $\mathrm{ERR}=1.387(95 \% \mathrm{CI}$ $0.753,2.554)$; pooled $\mathrm{ERD}=0.015(95 \% \mathrm{CI}$ $-0.002,0.033)$. However, the individual trial results are clinically heterogeneous and, when examined independently, the data from these studies might suggest an increased risk of necrotising enterocolitis in infants treated with prophylactic indomethacin.

\section{RENAL FUNCTION}

Rennie and Ment have reported the number of infants with decreased urine output. The pooled results show a small significant difference, suggesting the incidence of oliguria is increased in infants who receive prophylactic indomethacin (five trials, $2426313435 \quad 624$ infants); pooled $\mathrm{ERR}=1 \cdot 126(95 \%$ CI $1 \cdot 084$, $2 \cdot 748)$; pooled $\mathrm{ERD}=0.051$ ( $95 \%$ CI 0.009 , $0.092) ; \mathrm{NNT}=20$. Ment has also reported the number of infants in each group whose creatinine rose above $159 \mu \mathrm{mol} / /$. The pooled results show no difference between the groups (two trials, ${ }^{34} 35492$ infants); pooled $\mathrm{ERR}=0.924$ (95\% CI 0.298, 2.853); pooled ERD $=-0.001$ (95\% CI -0.028, -0.025). Mahoney ${ }^{23}$ reported mean serum sodium, potassium, and creatinine on day 3 as well as mean urine output over the first four days. There is no significant difference between the groups in any of these measures. Vincer ${ }^{26}$ reported mean serum sodium concentrations over the first seven postnatal days and points to a significantly higher concentration in the treatment group on days 3 and 4 . In addition to reporting reduced urine output in the treatment group, Rennie ${ }^{27}$ reported significantly higher peak creatinine on days 1 and 2 following treatment with indomethacin, but no significant difference in serum sodium concentrations. Krueger ${ }^{29}$ reported a significant reduction in urinary output (as measured by the input:output ratio)

Table 5 Results and meta-analysis of trials providing outcome data on symptomatic patent ductus arteriosus

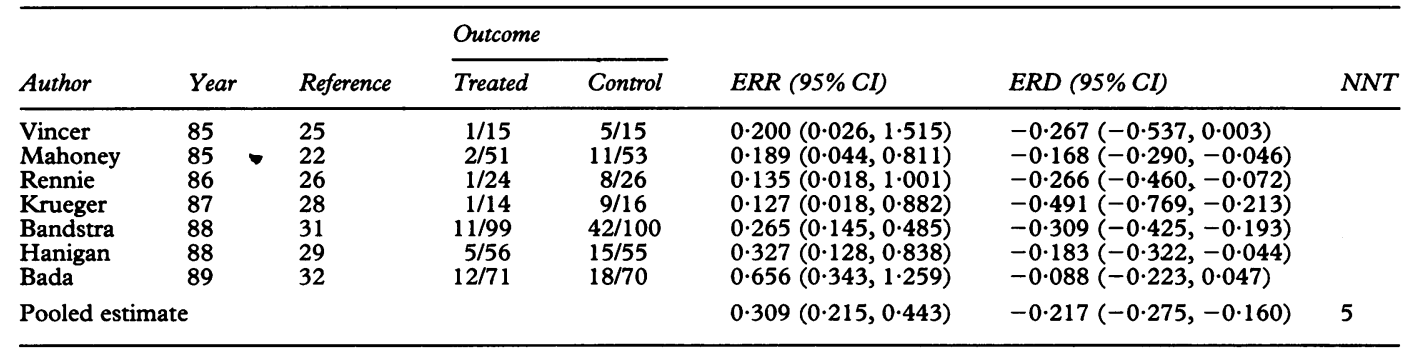


Table 6 Results and meta-analysis of trials providing outcome data on intraventricular haemorrhage

\begin{tabular}{|c|c|c|c|c|c|c|c|}
\hline \multirow[b]{2}{*}{ Author } & \multirow[b]{2}{*}{ Year } & \multirow[b]{2}{*}{ Reference } & \multicolumn{2}{|l|}{ Outcome } & \multirow[b]{2}{*}{$E R R(95 \% C I)$} & \multirow[b]{2}{*}{$E R D(95 \% C I)$} & \multirow[b]{2}{*}{$N N T$} \\
\hline & & & Treated & Control & & & \\
\hline $\begin{array}{l}\text { Vincer } \\
\text { Ment } \\
\text { Mahoney } \\
\text { Puckett } \\
\text { Rennie } \\
\text { Krueger } \\
\text { Hanigan } \\
\text { Bandstra } \\
\text { Ment } \\
\text { Bada } \\
\text { Ment }\end{array}$ & $\begin{array}{l}85 \\
85 \\
85 \\
85 \\
86 \\
87 \\
88 \\
88 \\
88 \\
89 \\
94\end{array}$ & $\begin{array}{l}26 \\
24 \\
23 \\
25 \\
27 \\
29 \\
30 \\
32 \\
31 \\
33 \\
35\end{array}$ & $\begin{array}{r}11 / 15 \\
6 / 24 \\
12 / 51 \\
15 / 16 \\
10 / 24 \\
4 / 14 \\
6 / 56 \\
43 / 99 \\
2 / 19 \\
27 / 71 \\
25 / 209\end{array}$ & $\begin{array}{l}8 / 15 \\
14 / 24 \\
17 / 53 \\
10 / 16 \\
9 / 26 \\
5 / 16 \\
11 / 55 \\
62 / 100 \\
8 / 17 \\
37 / 70 \\
40 / 222\end{array}$ & $\begin{array}{l}1.375(0.783,2.413) \\
0.429(0.199,0.927) \\
0.734(0.390,1.380) \\
1.500(1.006,2.237) \\
1.204(0.592,2.448) \\
0.914(0.394,2.750) \\
0.536(0.213,1.349) \\
0.701(0.534,0.921) \\
0.224(0.055,0.913) \\
0.719(0.496,1.041) \\
0.664(0.418,1.055)\end{array}$ & $\begin{array}{l}0.200(-0.137,0.537) \\
-0.333(-0.596,-0.070) \\
-0.085(-0.256,0.086) \\
0.312(0.047,0.577) \\
0.071(-0.198,0.340) \\
-0.027(-0.254,0.300) \\
-0.093(-0.226,0.040) \\
-0.186(-0.323,-0.049) \\
-0.365(-0.639,-0.091) \\
-0.148(-0.311,0.015) \\
-0.061(-0.28,0.006)\end{array}$ & \\
\hline \multicolumn{5}{|c|}{ Pooled estimate } & $0.741(0.632,0.867)$ & $-0.083(-0.129,-0.038)$ & 12 \\
\hline
\end{tabular}

affecting the treatment group in the 24 hours immediately following treatment. This difference is no longer apparent in the subsequent 24 hour period. In 1988, Ment reported no clinically important renal abnormalities but provides no data. ${ }^{31} \mathrm{Bada}^{33}$ provided data that show significant changes in plasma creatinine and sodium concentrations, osmolalities, and urine output, but comments that these differences were not abnormal - that is, not clinically important.

\section{HAEMOSTASIS}

Ment reported the number of infants whose platelet count fell to $<50 \times 10^{9} / 1$. The pooled result shows no evidence of a difference between the treatment and placebo groups (two trials, ${ }^{34}{ }^{35} 492$ infants); pooled $\mathrm{ERR}=0.502(95 \%$ CI $0.113,2.221)$; pooled $\mathrm{ERD}=-0.009(95 \%$ CI $-0.030,0.012)$. In the same two trials Ment also reported the number of infants who had 'excessive bleeding' and again the pooled result suggests no difference: pooled $E R R=0.860(95 \%$ CI 0.397 , 1.856); pooled $\mathrm{ERD}=-0.004 \quad(95 \% \quad \mathrm{CI}$ $-0.042,0.032$ ). Setzer ${ }^{22}$ provided data showing that platelet count is reduced and bleeding time prolonged following both active treatment and placebo. The data are analysed within subjects only and do not permit a reliable comparison between groups. Rennie ${ }^{27}$ suggested that treatment with indomethacin prolonged bleeding time. However, no direct comparison between the indomethacin group and the control group is offered and the data given do not permit further analysis.

\section{RETINOPATHY OF PREMATURTYY}

There is no evidence of a difference in the rates of retinopathy of prematurity between treatment and placebo groups (three trials, ${ }^{23} 2432$
306 infants); pooled $\mathrm{ERR}=1 \cdot 185$ (95\% CI $0.695,2.018)$; pooled $E R D=0.032(95 \%$ CI $-0 \cdot 046,0 \cdot 111$ ).

\section{SEPTIC EPISODES}

There is no evidence that prophylactic indomethacin has a significant effect on the incidence of septic episodes (two trials, 2332 303 infants); pooled $E R R=0.743$ (95\% CI $0.478,1.154)$; pooled $\mathrm{ERD}=-0.059(95 \%$ CI $-0 \cdot 150,0 \cdot 030$ )

\section{HETEROGENEITY AMONG TRIALS}

Some degree of clinical heterogeneity would not be unexpected, given that most of the studies reviewed are relatively small and there is obvious variation in study design (particularly birthweight eligibility criteria, the indomethacin dosage regimes used, and some of the outcome definitions). In fact, when considering the main apparent benefits of indomethacin - reduced incidence of $\mathrm{IVH}$ and PDA, the results of the trials examined seem, clinically, fairly homogeneous. The results on potential adverse effects of prophylaxis are more heterogeneous, however, suggesting caution should be used when interpreting any pooled estimates.

\section{Discussion}

This review and meta-analysis involved an extensive literature search and followed a rigorous protocol throughout. Several methodological and clinical issues are worth noting.

Although three electronic databases were searched, 67 of the 70 reports assessed for inclusion and all 14 of those finally included in the review were found in either the ODPT (40 reports), or Medline (33 reports), or both (16 reports). Only 14 reports were found in

Table 7 Results and meta-analysis of trials providing outcome data on grades 3 and 4 intraventricular haemorrhage

\begin{tabular}{|c|c|c|c|c|c|c|c|}
\hline \multirow[b]{2}{*}{ Author } & \multirow[b]{2}{*}{ Year } & \multirow[b]{2}{*}{ Reference } & \multicolumn{2}{|l|}{ Outcome } & \multirow[b]{2}{*}{$E R R(95 \% C I)$} & \multirow[b]{2}{*}{$E R D(95 \% C I)$} & \multirow[b]{2}{*}{$N N T$} \\
\hline & & & Treated & Control & & & \\
\hline $\begin{array}{l}\text { Ment } \\
\text { Krueger } \\
\text { Ment } \\
\text { Hanigan } \\
\text { Bandstra } \\
\text { Bada } \\
\text { Ment }\end{array}$ & $\begin{array}{l}85 \\
87 \\
88 \\
88 \\
88 \\
89 \\
94\end{array}$ & $\begin{array}{l}24 \\
29 \\
31 \\
30 \\
32 \\
33 \\
35\end{array}$ & $\begin{array}{l}1 / 24 \\
1 / 14 \\
0 / 19 \\
3 / 56 \\
19 / 99 \\
10 / 61 \\
3 / 209\end{array}$ & $\begin{array}{l}2 / 24 \\
5 / 16 \\
3 / 17 \\
3 / 55 \\
26 / 100 \\
15 / 70 \\
11 / 222\end{array}$ & $\begin{array}{l}0.500(0.049,5 \cdot 151) \\
0.229(0.030,1.734) \\
0.128(0.007,2.310) \\
0.982(0.207,4.656) \\
0.738(0.438,1.243) \\
0.765(0.371,1.577) \\
0.290(0.082,1.025)\end{array}$ & $\begin{array}{l}-0.042(-0.179,0.095) \\
-0.241(-0.506,0.024) \\
-0.174(-0.374,0.026) \\
-0.001(-0.085,0.083) \\
-0.068(-0.184,0.048) \\
-0.050(-0.183,0.083) \\
-0.039(-0.068,-0.002)\end{array}$ & \\
\hline \multicolumn{5}{|c|}{ Pooled estimate } & $0.601(0.415,0.868)$ & $-0.039(-0.066,-0.011)$ & 26 \\
\hline
\end{tabular}


Embase of which just three were unique to that database. None of these three unique reports was ultimately included in the review. In this study, therefore, Embase was not a sensitive database for identifying randomised controlled trials in neonatology.

Using strict criteria, two investigators independently and under blind conditions, selected and assessed the quality of articles for inclusion in this review. This technique, particularly when associated with a high degree of agreement between the investigators as in this study, greatly strengthens the validity of the results of systematic reviews. The same methodology or a similar approach should be a standard requirement in all scientific overviews.

No attempt was made to trace unpublished data and this is a potential source of bias in the review. In addition, even after combining trials where appropriate, the number of infants providing data on certain outcomes reported remains very small. As a result, although no evidence of a significant difference can be shown for some outcomes, this may be because of a lack of statistical power rather than the absence of a true treatment effect. This is reflected in the very wide $95 \%$ confidence intervals around some of the pooled estimates. On the other hand, achieving significance does not necessarily equate with clinical importance, and some of the significant differences seen between the treatment and placebo groups, especially in renal function parameters, are of doubtful clinical importance.

The methodological quality of the trials contributing to this review varied. Although eight of the studies fulfilled more than two of the four validity criteria, two (both reported in abstract only) did not fulfil any. No account of this was taken in the analyses presented here and future work might include using techniques in the meta-analysis that try to adjust for this variation. It is also not clear what effect the inclusion of abstracts has on any pooled estimates of treatment effect, regardless of their methodological quality as reported. Three abstracts were included in this review, two of which contributed data towards pooled estimates. Although both were reporting relatively small studies and might, therefore, be expected to have relatively little impact on the relevant pooled estimates, this needs to be confirmed. The trials also vary considerably in the total dose of indomethacin used $(0.2 \mathrm{mg} / \mathrm{kg}-0.6 \mathrm{mg} / \mathrm{kg})$. If higher doses were found to be more effective, it might also be that higher doses were associated with more adverse side effects. This may then have implications when trying to determine the overall impact of treatment and needs further investigation.

Clinically, using the number needed to treat, this study suggests that if 100 infants were to be treated with prophylactic indomethacin, one might expect to see eight fewer infants with intraventricular haemorrhages (four of grades 3 or 4), 24 fewer infants with a PDA (20 of which were symptomatic), and possibly a reduction in overall neonatal mortality. This apparent benefit would be at the 'expense' of having five 'extra' infants with an episode of reduced urine output and, perhaps, an increase in the incidence (indeterminate at this time) of necrotising enterocolitis. Unfortunately, there are virtually no data reporting long term outcomes. Just one study (reported in abstract form) provides data on neurodevelopmental outcome on babies at between 12 and 24 months of age. The results are inconclusive and very difficult to interpret given the small number of infants contributing data and the nature of the report.

\section{Conclusion}

Although there is evidence to suggest immediate benefit, prophylactic indomethacin cannot yet be recommended for routine use. More data are needed on long term neurodevelopmental outcomes and possible adverse effects, especially the incidence of necrotising enterocolitis and clinically important episodes of impaired renal function. Future investigation, either new trials or further assessment of infants enrolled in previous studies, should be specifically directed at collecting these data as well as determining an optimal dosage regimen. Subgroup analyses on the basis of birthweight, gestation, and perhaps initial illness severity would also be worthwhile.

Dr Sean Dinneen assisted in the article selection and evaluation process. Professor John C Sinclair provided expert advice on methodology and Professor Michael Bracken helped with the statistical analyses. Dr Fowlie was supported by an MRC (UK) Training Fellowship in Health Services research.

1 Brown ER. Increased risk of bronchopulmonary dysplasia in Brown ER. Increased risk of bronchopulmonary dysplasia in 865 .

2 Kitterman JA, Edmunds LH Jr., Gregory GA, Heymann MA, Tooley WH, Rudolph AM. Patent ductus arteriosus in premature infants: incidence and relation to pulmonary disease and management. $N$ Eng $\mathcal{F}$ Med 1972; 287: 473.

3 Heymann MA, Rudolph AM, Silverman NH. Closure of the ductus arteriosus in premature infants by inhibition of prostaglandin synthesis. N Engl f Med 1976; 295: 530-3.

4 Lipman B, Server GA, Brazy JE. Abnormal cerebral haemodynamics in preterm infants with patent ductus arteriosus. Pediatrics 1982; 69: 778-81.

5 Ment LA, Stewart WB, Duncan CC, Scott DT, Lambrecht R. Beagle puppy model of intraventricular haemorrhage: R. Beagle puppy model of intraventricular haemorrhage: effect of indomethacin on
surgery $1983 ; 58: 857-62$.

6 Ment LA, Stewart WB, Ardito TA, Huang E, Madri JA. Indomethacin promotes germinal matrix maturation in the newborn beagle puppy. Stroke 1992; 23: 1132-7.

7 Edwards AD, Wyatt JS, Richardson C, Potter A, Cope M, Delpy DT, et al. Effects of indomethacin on cerebral haemodynamics in very preterm infants. Lancet 1990; 335: 1491-5.

8 Coombs RC, Morgan MEI, Durbin GM, Booth IW, McNeish AS. Gut blood flow velocities in the newborn: effects of patent ductus arteriosus and parenteral indomethacin. Arch Dis Child 1990; 65: 1067-71.

9 Cifuentes RF, Olley PM, Balfe JW, Radde IC, Soldin SJ. Indomethacin and renal function in premature infants with persistent patent ductus arteriosus. $\mathcal{F}$ Pediatr 1979; 95: 583-7.

10 Friedman $Z$, Whitman V, Maisels MJ, Berman WJr, Marks KH, Vessell ES. Indomethacin disposition and indomethacin-induced platelet dysfunction in premature infants. F Clin Pharmacol 1978; 18: 272-9.

11 Herson VC, Krause PJ, Eisenfeld LI, Pontius L, Maderazo EG. Indomethacin associated sepsis in the very low birth weight infant. $A m \mathcal{F}$ Dis Child 1988; 142: 555-8.

12 Mulrow CD. The medical review article: state of the science. Ann Intern Med 1987; 106: 485-8.

13 Moher D, Jadad AR, Nichol G, Penam M, Tugwell $P$, Walsh S. Assessing the quality of randomized controlled trials: an annotated bibliography of scales and checklists. trials: an annotated bibliography of scales

14 Schultz KF, Chalmers I, Hayes RJ, Altman DG. Empirical evidence of bias; dimensions of methodologic quality associated with estimates of treatment effect in controlled clinical trials. $\Im A M A$ 1995; 273: 408-12.

15 Bada HS, Green RS, Pourcyrous M, Leffler CW, Korones $\mathrm{SB}$, Arheart $\mathrm{K}$. Indomethacin reduces relative risks of severe intraventricular haemorrhage. Ped Res 1989; 25: 353A. 
16 Bandstra ES, Bauer CR, Duenas ML, Chao H, Montalvo BM, Bancalari E. Prophylactic indomethacin for prevention of intraventricular haemorrhage: neurodevelopmental follow-up. Ann Neurol 1987; 22: 427A.

17 Pourcyrous M, Bada HS, Green RS, Korones SB. Safety of indomethacin use for newborn infants. Ped Res 1988; 23: 422A.

18 Setzer ES, Morse BM, Goldberg RN, Smith M, Bancalari E. Prophylactic indomethacin and intraventricular E. Prophylactic indomethacin and intraventricular

19 Setzer ES, Torres-Arraut E, Gomez-del-Rio M, Young ML, Pacheco I, Ferrer PL, et al. Cardiopulmonary effects of prophylactic indomethacin in the very low birth weight infant. Ped Res 1984; 18: 346A

20 Rothman KJ. In: Modern epidemiology. Boston: Little Brown, 1986

21 Bracken MB. Statistical methods for analysis of effects of treatment in overviews of randomised trials. In: Sinclair $\mathrm{JC}$, Bracken $\mathrm{MB}$, eds. Effective care of the newborn infant. New York: Oxford University Press, 1992: 13-20.

22 Setzer ES, Smith M, Goulding PJ, Bandstra TE. Severity of platelet dysfunction induced by prophylactic of platelet dysfunction induced by prophylactic 346A. 23 Mahoney L, Caldwell RL, Girod DA, Hurwitz RA, Jansen
$\mathrm{RD}$, Lemons JA, et al. Indomethacin therapy on the first day of life in infants with very low birth weight. $\mathcal{f}$ Pediatr 1985; 106: 801-5.

24 Ment LR, Duncan CC, Ehrenkranz RA, Kleinman CS, Pitt $\mathrm{BR}$, Taylor KJ, et al. Randomized indomethacin trial for prevention of intraventricular haemorrhage in very low birth weight infants. $\mathcal{f}$ Pediatr 1985; 107: 937-43.

25 Puckett CG, Cox MA, Haskins KS, Fisher DJ. Prophylactic indomethacin (I) for the prevention of patent ductus arteriosus (PDA). Ped Res 1985; 19: 358A.

26 Vincer V, Allen A, Evans J, Nwaesei C, Stinson D, Rees E, et al. Early intravenous indomethacin prolongs respiratory support in very low birth weight infants. Acta Paediatr Scand 1985; 76: 894-7.

27 Rennie JM, Doyle J, Cooke RWI. Early administration of indomethacin to preterm infants. Arch Dis Child 1986; 61 233-8.

28 Bandstra ES, Duenas ML, Rodriguez I, Chao H, Montalvo BM, Bauer CR, et al. Prophylactic indomethacin for the prevention of intraventricular haemorrhage (IVH): neuprevention of intraventricular haemorrhage (IVH):

29 Krueger E, Mellander M, Bratton D, Cotton R. Prevention of symptomatic patent ductus arteriosus with a single dose of symptomatic patent ductus arteriosus with a sing
of indomethacin. $₹$ Pediatr $1987 ; 111: 749-54$.

30 Hanigan WC, Kennedy G, Roemisch F, Anderson $R$ Cusack T, Powers W. Administration of indomethacin for the prevention of periventricular haemorrhage in high-risk neonates. $\mathcal{F}$ Pediatr 1988; 112: 941-7.

31 Ment LR, Duncan CC, Ehrenkranz RA, Kleinman CS Taylor KJW, Scott DT, et al. Randomized low-dose indomethacin trial for prevention of intraventricula haemorrhage in very low birth weight neonates. f Pediatr 1988; 112: 948-55.

32 Bandstra ES, Montalvo BM, Goldberg RN, Pacheco I, Ferrer PL, Flynn J, et al. Prophylactic indomethacin for prevention of intraventricular haemorrhage in premature prevention of intraventricular haem
infants. Pediatrics 1988; 82: 533-42.

33 Bada HS, Green RS, Pourcyrous M, Leffler CW, Korones $\mathrm{SB}$, Magill HL, et al. Indomethacin reduces the risks of severe intraventricular haemorrhage. f Pediatr 1989; 115 631-7.

34 Ment LR, Oh W, Ehrenkranz RA, Phillip AGS, Vohr B, Allan W, et al. Low-dose indomethacin therapy and extension of intraventricular haemorrhage: a multicentre randomized trial. 7 Pediatr 1994; 124: $951-5$.

35 Ment LR, Oh W, Ehrenkranz RA, Phillip AGS, Vohr B, Allan W, et al. Low-dose indomethacin and prevention of intraventricular haemorrhage: a multicentre randomized intraventricular haemorrhage: a
trial. Pediatrics 1994; 93: 543-50. 